\title{
A gestão estratégica dos hospitais na França: balanço e perspectivas
}

\author{
Strategic management of hospitals in France: \\ balance and perspectives
}

${ }^{1}$ Groupe HEC Paris - Ecole deshautesétudes commerciales. 1 Ruedela Libération 78350 J ouy en Josas, France, 0139677000. cremadez@hec.fr
Abstract The strategic management was introduced in French hospitals in the late $80 \mathrm{~s}$, in a context of inefficiency and the need to control healthcare expenditure. This concept has inspired a series of government reforms, the organization and dynamics of hospitals and the mode of regulating the French health system, assuming a real change of professional culture. The changes in the economic context and in the finance of hospitals, the behavior of users, the population aging, the development of chronic diseases and increased competition, are the new challenges to be faced. The involvement of stakeholders is crucial and the strategic management, based on mobilizing these actors, is today, a method of administration particularly well adapted to the health area. This article aims to present the impact of the concept of strategic management in the evolution of French hospitals and the consequences of these developments on the outl ook for the dissemination of strategic management in the health sector. To do so, it is examined the evolution of the French context until 2010, the new challenges that French hospitalsmust faceand, finally, the consequences of these challenges on how to design services, manage the relationships between the actors of the health system and organize the operational functioning of hospitals.

Key words Strategic management, H ospital management, O rganizational change, $\mathrm{N}$ etworks of coordinated care, Patient's journey
Resumo A gestão estratégica é introduzida nos hospitais franceses no final da década de oitenta, num contexto de ineficácia e necessidade de controledas despesas desaúde. Esteconceito tem inspirado uma série de reformas do governo, da organização e da dinâmica dos hospitais e do modo de regulação do sistema de saúde francês, pressupondo uma verdadeira mudança da cultura profissional. As mudanças no contexto econômico eno modo de financiamento doshospitais, no comportamento dosusuários, 0 envelhecimento da população, 0 desenvolvimento das patologias crônicas ea intensificação da concorrência, constituem novos desafios a serem enfrentados. 0 envolvimento dos atores é fundamental ea gestão estratégica, baseada na mobilização dosatores, torna-se, hoje, um modo deadministração particularmente adaptado à área da saúde. Este artigo tem por objetivo apresentar o impacto do conceito degestão estratégica na evolução do meio hospitalar francês eas consequências desta evolução sobreas perspectivas de difusão da getão estratégica no setor da saúde. Para isso, examina-se a evolução do contexto francês até 2010, os novos desafios que os hospitais franceses devem enfrentar e, por fim, as consequências destes desafios sobre a maneira de conceber os serviços, de administrar as relações entre os atores do sistema de saúde e de organizar o funcionamento operacional dos hospitais. Palavras-chave Gestão estratégica, Gestão hospitalar, M udança organizacional, Redes de cuidados coordenados, Percurso do paciente 
Introdução

No final dos anos oitenta, a ideia de envolver os médicos na gestão hospitalar francesa começa a ganhar corpo eisto ocorre num contexto de ineficácia do control e financei ro para limitar o crescimento das despesas de saúde. N essa época, che ga-se à conclusão de que a introdução, em 1983, do orçamento global, como modo de financiamento dos hospitais, não ensejou os resultados esperados. 0 orçamento global desvincula os recursos dos hospitais do volume de atendimento realizado efinancia uma capacidade prévia de atendimento na perspectiva de limitar as despe sas dos hospitais pelo controle da oferta de serviços. N este caso, a principal condição de eficácia do sistema corresponde à capacidade dos hospitais de respeitar o orçamento fixado, o que, infelizmente, não acontecena maioria das vezes. Para respeitar seu orçamento, um hospital tem que racionalizar sua oferta de atendimento, por um lado, e, por outro lado, fazer esforços de aumento da produtividade, duas providências quepressupõem uma cultura de gestão e ferramentas específicas que ainda não existiam.

A introdução da gestão estratégica nos hospitais franceses tenta compensar estas duas fraquezas ${ }^{1}$. Fundado na abertura para 0 ambiente externo, na partici pação ampla dos atores internos e no uso dos instrumentos de análise estratégica, este modelo de gestão estratégica surge com o objetivo de provocar as mudanças culturais e técnicas necessárias. A gestão estratégica provoca a difusão, pelo interior da organização, das preocupações que a divisão vertical do trabalho atribui unicamente aos níveis superiores da direção? .

0 envolvimento dos médicos na reflexão estratégica é fundamental para mudar a cultura interna. Através da análise estratégica, eles percebem que atuar sobre o ambiente externo é possível, sob a condição de raciocinar sobre o todo institucional e de fazer escolhas coletivas. Esta análise permitesituar o hospital no contexto global de atendimento, ressaltando a importância de uma abordagem sistêmica das relações entre os atores profissionais, individuais ou institucionais, da saúde. Ela transforma a dinâmica interna, reforçando a cooperação, na reflexão e na ação, entre os atores profissionais, gerando uma visão comum dos desafios e quebrando as barreiras iniciais. Este processo, de início limitado a al guns hospitais pioneiros, frequentemente dirigidos por ex-alunos do programa de capacitação de diretores de hospitais, concebido e opera- cionalizado sob a direção de Christian Cauvin e Michel Crémadez, na Escola de Altos Estudos Comerciais, passa a ser difundido eacelerado nos hospitais franceses pela promulgação da lei de 31 dejulho de 1991, queobriga os hospitais a el aborar um projeto de estabelecimento com uma perspectiva de cinco anos.

Este artigo tem por objetivo estudar $0 \mathrm{im}$ pacto do conceito de gestão estratégica na evolução do meio hospitalar francês e as consequências desta evolução sobre as perspectivas de difusão da gestão estratégica no setor da saúde. Para isso, examinaremosa evolução do contexto francês até 2010, os novos desafios que os hospitais franceses devem enfrentar e, por fim, as consequências destes desafios sobre a maneira de conceber os serviços, de administrar as relações entre os atores do sistema de saúde e de organizar o funcionamento operacional dos hospitais.

\section{A evolução do contexto francês}

O sistema de saúde francês assiste a partir dos anos noventa a uma aceleração das mudanças tanto no nível da regulamentação, reconhecendo uma série importante de reformas, como no nível econômico, caracterizado por um movimento amplo de reestruturação do financiamento e da oferta de serviços.

\section{0 contexto econômico}

Este é caracterizado por três evoluções principais: a implicação crescente dos atores privados no financiamento do sistema de seguro social, o abandono do orçamento global e a concentração da oferta de serviços.

N os países desenvolvidos, a evolução do conceito de saúde para o conceito de bem-estar traz mais dificuldades para o financiamento do sistema de saúde. 0 resultado é a transferência crescente da carga do seguro social para os seguros complementares eas pessoas físicas, através principalmente do não reembolso de certos medicamentos e de certos tipos de atendimento.

$\mathrm{Na}$ França, o abandono do orçamento global em prol da tarifa ligada à atividade (T2A), instaurada em 2005, aplicada progressivamente e generalizada em janeiro 2008, constitui uma nova tentativa de controle das despesas de saúde ligadas aos serviços prestados pelos hospitais. Ao substituir a regulação baseada na oferta pela regulação baseada na demanda, a T2A implica uma mudança do raciocínio estratégico e da di- 
nâmica interna dos estabelecimentos de saúde. No nível estratégico, a atração dos pacientes se torna, ao contrário do que acontecia com o orçamento global, o elemento central da concorrência. No nível técnico, a T2A introduz o conceito de margem na gestão hospitalar, quetem como principal consequência a necessidade de conhe cer e administrar o custo dos serviços, considerando que estes custos estão diretamente ligados à qualidade e aos prazos de atendimento. Para ser bem-sucedido neste novo contexto, é necessário antecipar, fazer previsões de atividades, ter uma atuação sobre os fluxos de pacientes, administrar as interfaces entre os diferentes atores ao longo das linhas de cuidado, investir tempo na concepção e na formalização dos serviços oferecidos, avaliar as práticas profissionais, o que transforma fundamentalmente a dinâmica organizacional e a cultura hospitalar.

Desde o início dos anos noventa, a França enfrenta uma forte concentração da oferta de serviços de saúde, ligada a dois el ementos que se reforçam mutuamente: o nível de investimento necessário (blocos operatórios, serviços de imagem) e as normas de volume de atendimentos necessários para atingir o grau de qualidade e de segurança requerido pela alta autoridade de saúde (H auteAutorité de la Santé- HAS). Assim, no campo das clínicas privadas, o tamanho médio das unidades semultiplica por quatro em quinze anos, com uma mudança dos acionistas e construção de grupos por crescimento externo. No setor público, a vontade de racionalizar a oferta provoca operações de fusão que são feitas com muita dificuldade devido ao fato de que o hospital é sempre o principal empregador numa cidade e um dos serviços-chave para a população.

No mesmo período, com um impacto diferenciado em função das patologias e das modalidades de organização do seguro social nos diferentes países, o campo concorrencial se alarga. Cria-se um espaço na comunidade européia, no qual o paciente tem que ser reembolsado por um atendimento realizado num outro país da comunidade, se este atendimento não for acessível em seu próprio país. Este fenômeno é reforçado pelo desenvolvimento da concorrência no nível mundial, nos campos não ou mal reembolsados pel os seguros sociais e os seguros complementares dos países desenvolvidos, por parte de certos países emergentes, como Singapura e Tailândia, por exemplo.

\section{O contexto regulamentar}

$\mathrm{Na}$ França, as numerosas medidas regulamentares adotadas procuram adaptar o funcionamento dos hospitais ao novo contexto estratégico. Elas visam aumentar a responsabilidade dos atores profissionaiseinstitucionaisea transparência do sistema de saúde. Cronologicamente, seis medidas aparecem como as mais estruturantes:

1. A lei de 31 de julho de 1991 obriga os hospitais públicos a analisar suas atividades. Para isso, é implementado o Programa de M edicalização dos Sistemas de Informações (PM SI), fundamentado nos resultados do "projeto de medicalização dos sistemas de informações" iniciado em 1982, baseado no trabalho do professor Robert Fetter e sua equipe (a Universidade de Yale nos Estados Unidos). Com base neste programa, é definida para os hospitais a obrigatoriedade de transmitirem seus dados de atividade para uma base nacional de custos. M ais tarde, os estabelecimentos privados também são levados a implementar o PM SI. A pesar de reforçar a pressão exercida sobre os hospitais, os constrangimentos normativos pertinentes não conseguem evitar as dificuldades ligadas à cultura médica. A inércia oposta por uma parte dos médicos freia o processo, impedindo a necessária exaustividade da coleta de dados. Só a reforma do sistema de financiamento dos hospitais permitirá, a partir de 2005, ultrapassar as últimas barreiras e resultar na integração total do sistema de registro das atividades ao funcionamento dos serviços médicos ena suautilização pela maioria dos profissionais que dispõem, assim, de uma ferramenta para analisar e medir suas atividades.

2. Em 1997, são implementadas as Agências Regionais dos $\mathrm{H}$ ospitais (ARH), criadas pela portaria de 24 de abril de 1996, chamada de reforma "Juppé", nome do primeiro ministro da saúde na época. Esta reforma substitui o planejamento centralizado por um planejamento regional, que comporta um enfoque de regulação do sistema de saúde, envolvendo os profissionais. Em janeiro de2010, a partir da lei H ospital, Paciente, Saúde e Território ( $n^{\circ} 2009-879$, de 21 de julho de 2009), as ARH são transformadas em Agências Regionais de Saúde (ARS), encarregadas de administrar todos os componentes do sistema regional de saúde e de segurança social (Figura 1). 


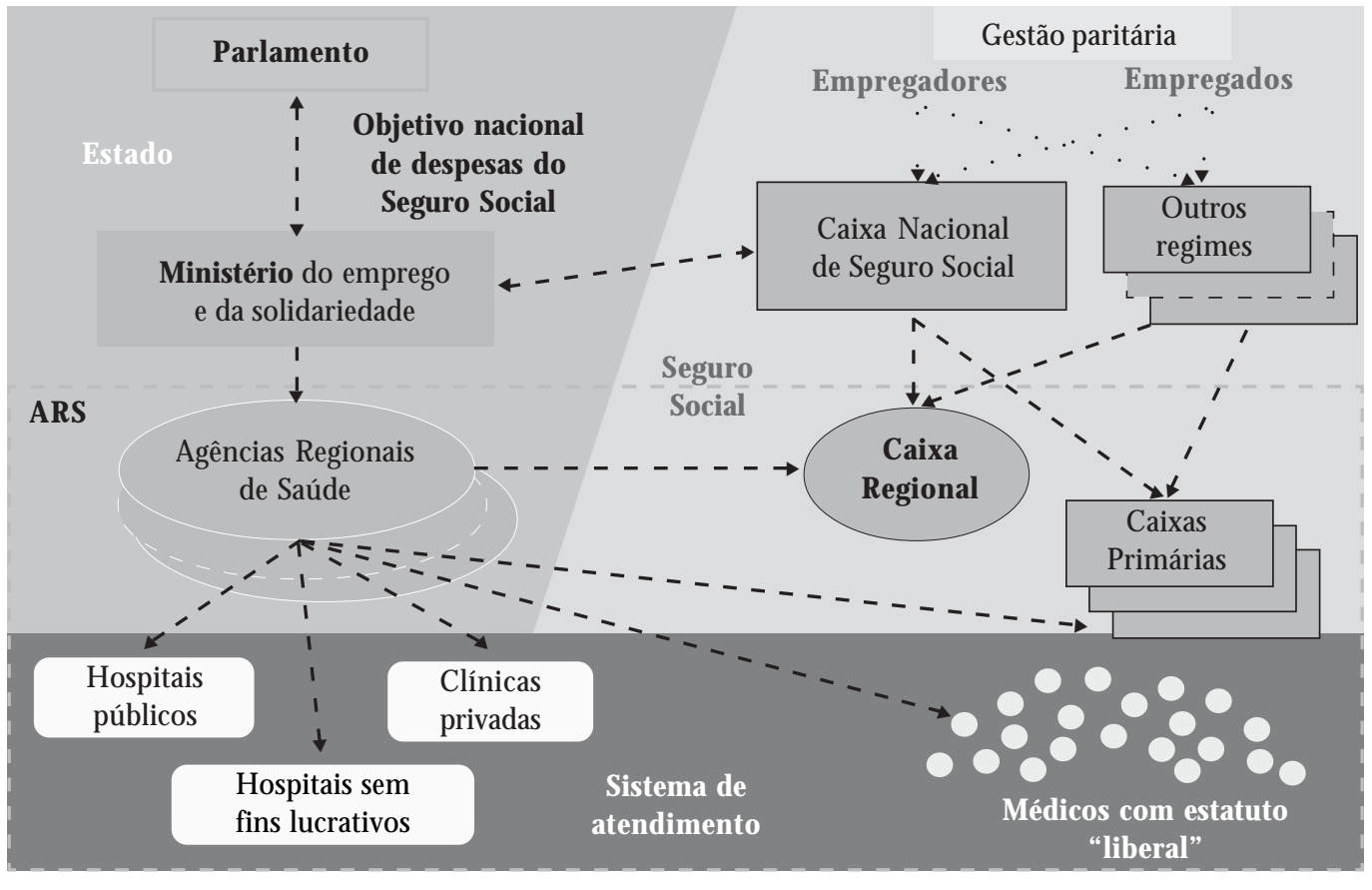

Figura 1. 0 sistema de saúde e de seguro social após a lei HPST.

3. A circular DH/AF/AF $3 n^{\circ} 97-304$, de 21 de abril de 1997, reforça a prática dos convênios internos entre a direção e os serviços de cuidado, instaurada, de maneira facultativa, pela Portaria $n^{\circ}$ 96-346, de 24 de abril de 1996. Esta medida visa a uma desconcentração dos procedimentos de decisão internos, como contrapartida da formalização dos objetivos e dos planos de atuação das unidades de atendimento, e busca incentivar o diálogo interno entre a direção e os serviços de atendimento do hospital ${ }^{3}$.

4. A lei de 13 de agosto de 2004 cria a alta autoridade da saúde (Haute Autorité de Santé HAS), integrando num órgão único a agência nacional de credenciamento e outras comissões. Esta autoridade avalia a utilidade médica dos serviços e produtos reembolsados pelo seguro social, formula recomendações independentes e imparciais quanto ao reembolso destes produtos e serviços, desenvolve as boas práticas profissionais e credencia os estabelecimentos de saúde. N esta perspectiva, o Decreto $n^{\circ}$ 2005-346, de 14 de abril de 2005, submete todos os médicos à obrigação de avaliação de suas práticas profissionais (EPP). A EPP tem por objetivo a melhoria contínua da qualidade do serviço fornecido aos pacientes (qualidade, segurança, eficácia, eficiência). Para isso, as práticas dos médicos são comparadas com referenciais ou recomendações validadas pela HAS com o fim de implementar ações de mel horia das práticas numa perspectiva de capacitação contínua, cuja originalidade se encontra em ser um processo de caráter coletivo no interior do hospital. Assim, os médicos que pertencem à mesma especialidade trabal ham juntos para realizar uma autoavaliação.

5. O plano "Hospital 2007" modifica o sistema de governo dos hospitais públicos ao criar 0 comitêexecutivo, órgão deadministração no qual são reunidos, de maneira paritária, médicos e administradores. Paralelamente, a partir de2006, é implementada uma reorganização interna segundo a qual os serviços médicos são, a princípio, agrupados em polos de atividades ${ }^{1}$.

6. Em 23 deoutubro de 2009, écriada a Agência Nacional para a Performance do Sistema de Saúde (ANAP), encarregada do aprimoramento da gestão, que reúnetrês entidades: o Grupo para a M odernização do Sistema de Informação H ospitalar (GM SIH), a M issão Nacional de Apoio ao Investimento Hospitalar (M AINH) e a M issão Nacional de Expertise e de Auditoria Hospi- 
talar (M EAH), sob a forma jurídica de um Grupo de Interesse Público (GIP).

Ao reforçar a dimensão institucional do hospital e o envolvimento dos médicos na sua gestão, estas reformas, em parte inspiradas no conceito de gestão estratégica, criam um contexto altamente favorável a seu desempenho. Reciprocamente, a prática da gestão estratégica facilita a modificação da dinâmica interna dos hospitaise da cultura médica. Assim, a gestão estratégica aparece, acima de tudo em 2010, como o modo de administração adequado. Em que medida ele pode permitir enfrentar, com sucesso, os novos desafios com os quais os hospitais são confrontados é o que buscamos agora examinar.

\section{Osnovos desafios estratégicos}

Os principais desafios estratégicos para os hospitais franceses são: enfrentar as mudanças nas necessidades, no comportamento dos usuários, na concepção do atendimento enas expectativas dos profissionais de saúde. $\mathrm{Na}$ resposta a estes desafios está o desafio de inovar na concepção e na operacionalização dos serviços oferecidos.

\section{Do paciente ao cliente}

M ais consciente do valor que gasta, e pagando mais cada ano para os serviços de saúde, o usuário vem mudando de comportamento. Ele apresenta uma ten dência a adotar uma atitude de consumo, fazendo arbitragem entre saúde e outros serviços. Esta mudança é acentuada pela facilidade deacesso aos conhecimentos científicose técnicos pelaI nternet. A disponibilidadedeinformações antes exclusivamente reservadas aos profissionais num contexto em que a dimensão virtual prevalece, dáaos pacientes um sentimento de competência que enfraquece a autoridade ligada ao saber. Assim, a necessária relação de confiança entre o médico e o paciente se fundamenta mais na qualidade percebida do serviço prestado. N este sentido, os profissionais devem reconhecer 0 caráter múltiplo do papel do usuário do hospital. Atuar com uma pessoa sendo ao mesmo tempo um paciente, um cliente, um membro da equipe multiprofissional que cuida dele, supõe adotar uma postura mais aberta e mais flexível.

A transgressão de outro tabu reforça a modificação da relação de poder. No final dos anos noventa, os serviços de saúde começam a ser avaliados publicamente por jornalistas que desejam compensar a ausência de transparência dos hos- pitais e a escassez de informações provenientes dos profissionais. Periódicos como "Le Point" ou "L'Express", equivalentes a "Isto é" ou "Veja" no Brasil, se inserem nesta linha de avaliação, promovendo classificações dos hospitais. Esta política passa a ser aceita pelos profissionais, que se esforçam para preencher os questionários usados para obter a informação com cuidado. Ter a melhor posição possível nas classificações é fundamental para a imagem do hospital.

N este contexto, atrai 0 cliente torna-se fundamental. 0 mais aberto, o mais transparente, 0 mais atento às preocupações e aos critérios de satisfação dos clientes tem a maior probabilidade de sucesso. M ais ainda, o hospital tem de responder às necessidades de clientes múltiplos, intermediários, financiadores, tutela administrativa, parceiros externos e atores internos. Para satisfazer todos estes clientes, o hospital deve ter uma visão sistêmica, praticar uma abordagem global, elaborar respostas integradas, como supõe a prática da gestão estratégica.

\section{As mudanças}

na concepção do atendimento

Oshospitaisfranceses estão organizados principalmente para praticar um atendimento pontual, mobilizando recursos técnicos sofisticados e competências especializadas. Esta abordagem caracteriza também a cultura médica, gerando um grau crescente de especialização dos profissionais, ainda pouco compensado pela qualidade do trabal ho coletivo. A reatividadeéa preocupação principal. Os profissionais estão centrados no curtíssimo prazo, o que dificulta o relacionamento interno eexterno efavorece o fechamento na prática cotidiana. Isso não facilita a comunicação ea transparência. Os pacientes frente a esta opacidade do sistema de saúde estão isolados e pouco aparelhados para a busca do melhor especialista. Eles devem utilizar as redes informais de relacionamento, cuja confiabilidade não é comprovada, procurar soluções sem a certeza de ter a resposta adequada.

Ao contrário, as novas necessidades ligadas ao envelhecimento da população, ao atendimento das pessoas idosas e dependentes, ao desenvolvimento das doenças degenerativas e crônicas e de seus fatores de riscos, como tabagismo, sobrepeso, uso excessivo de álcool e outras drogas, re querem uma abordagem diferente. $\mathrm{Na}$ atenção repetitiva, os fatores-chave de sucesso não são os mesmos. Ter uma visão de médio prazo, compartilhar as informações, conservar uma "memó- 
ria" dos atos realizados, tudo isso éindispensável. A antecipação, a prevenção secundária, a ligação e a coordenação das diferentes etapas do atendimento, através de uma explicitação euma formalização das linhas de cuidado e uma gestão das interfaces, tornam-se fundamentais. As expectativas dos pacientes confrontados com estes problemas de saúde também são diferentes. Eles esperam sempre encontrar uma capacidade de reação forte por parte do meio hospitalar, mas estão ainda mais preocupados com ter perspectivas claras de médio prazo. 0 desenho do percurso de atendimento, a qualidade das informações recebidas, e 0 acompanhamento ao longo do caminho são suas principais preocupações. Eles adotam um comportamento de cliente fiel quando acham respostas deste tipo, com todas as vantagensque estecomportamento oferece ao fornece dor do serviço, principalmente quando o fato de atrair e conservar a clientela determina o sucesso.

Assim, o socorro pontual deacidentes desaúde deixa de ser o único modo de atendimento. A saúde pública, a prevenção, 0 acompanhamento a médio e longo prazo conquistam novos espaços, abrindo novas perspectivas para a gestão estratégica, tanto no nível operacional como no nível político. Isto é obviamentefavorecido pelo alargamento do campo de raciocínio dos profissionais de saúde e pela necessidade crescente de atuar de maneira proativa.

\section{Atrair e conservar}

os melhores profissionais

O uso da T2A como principal instrumento de regulação do sistema hospitalar se acompanha deum alívio da regulamentação e da diminuição do número dos equipamentos submetidos a autorizações da tutela. Na concorrência para a captação de recursos, atrair e conservar um pessoal competente e motivado, em quantidade adequada, se torna essencial. Três tipos de fatores combinados explicam esta evolução. No nível político eestrutural, as exigências crescentes em termos de normas de trabalho (descanso compensatório, diminuição do tempo de trabal ho para 35 horas por semana, etc.) ea limitação do número deprofissionais de saúde formados criam uma escassez de recursos humanos e reforçam a competição para detêlos. No nível social e individual, a vontade de manter um equilíbrio entre vida profissional e pessoal diminui o grau de empenho dos profissionais, a profissão se banaliza e os critérios de escolha dos empregados mudam. A concepção do desempenho profissional evolui. A carrei- ra médica, por exemplo, caracterizada anteriormente por uma fraca mobilidade profissional e geográfica, torna-se mais móbil. Esta evolução provoca uma mudança nas políticas de gestão dos recursos humanos. Nos grupos de clínicas privadas, o estatuto liberal dos médicos começa a ser questionado, o controle deste recurso-chave aparece como essencial numa estratégia de grupo. Uma reflexão criativa para conceber e oferecer perspectivas decarreirainternas seinicia. No campo público, a formação médica contínua deixa de ser unicamente papel do grupo profissional para tornar-se uma preocupação institucional, pelo fato de ser a alavanca fundamental para provocar as mudanças culturais, promover a cooperação interna, o trabalho em equipemultiprofissional e lutar contra o corporativismo.

Esta evolução reforça também a importância de praticar a gestão estratégica na medida em que outorga aos atores um papel central, encorajando o envolvimento pessoal e liberando as iniciativas.

A necessidade de inovar

na prestação de serviços e na eficiência

A implementação da T2A leva os hospitais a uma situação de constrangimentos resultante da seguintedinâmica. M étodo de financiamento inflacionário, por natureza, aT2A não permite garantir o cumprimento da meta nacional dos custos de seguro de saúde (ONDAM), forçando 0 seguro social a praticar uma redução anual das tarifas como compensação. A esta tendência se junta uma cobrança constante das normas de qualidade por parte da alta autoridade para a saúde (HAS). Condenados a realizar um esforço contínuo de produtividade, sem possibilidadede ter uma política própria de preços, os hospitais precisam inovar na concepção dos serviços e na eficiência para encontrar novas margens de liberdade. N este sentido, para que possam se beneficiar de transferências de financiamento do seguro social para os seguros complementares e para as pessoas, precisam responder as necessidades solventes dos clientes que não são cobertos pela solidariedadenacional. N a busca de uma maior eficiência nos serviços que oferecem, devem tirar proveito das reservas de produtividade relativas ao aprimoramento das relações com os outros atores do sistema de saúde. No entanto, essa otimização conjunta no valor dos serviços e nos custos subsequentes não é o mais fácil de se conseguir em uma área como a saúde, no qual a ética éessencial. 
Uma vez mais, o sucesso nesta busca depende das capacidades de abertura, de escuta ederelacionamento, tanto externo como interno, o que torna a prática da gestão estratégica fundamental.

\section{Asconsequências dos desafios nos campos estratégico e operacional}

Responder aos desafios descritos gera uma série de consequências tanto estratégicas como operacionais. Em termos estratégicos, há que se pensar diferentementea concepção dos serviços eas relações entre os atores do sistema de saúde. Em termos operacionais, é necessário pensar diferentementea operacional ização dos serviçose o relacionamento entre os atores dentro dos hospitais.

\section{As consequências estratégicas}

Em primeiro lugar, épreciso entender eantecipar a evolução das expectativas e do comportamento dos clientes num sentido amplo. Os clientes finais esperam soluções capazes de resolver seus problemas e não simplesmente serviços iso- lados. $\mathrm{Na}$ área da saúde, este fenômeno, perfeitamente perceptível com relação aos automóveis (o que importa mais éa mobilidade não a posse de um automóvel), está acontecendo. Confrontados com estas expectativas nascentes, os seguros mutuais, por exemplo, estão criando plataformas telefônicas para informar os pacientes sobre os recursos disponíveis, a qualidade do atendimento, a competência dos profissionais de saúde, o custo do atendimento e facilitar, assim, suas escolhas. No mesmo sentido, as redes de cuidado se desenvolvem desde os anos oitenta para coordenar a atuação dos profissionais e acompanhar os pacientes que sofrem de certas doenças como diabetes, câncer, etc., ou simplesmente pessoas idosas e dependentes.

Para elaborar estas respostas globais, éindispensável considerar a pessoa em todas suas dimensões, fisiológica, psicológica e social, e não restringir a visão à doença ou ao órgão doente (Figura 2).

De certo modo, esta é uma maneira eficaz de concretizar o discurso muito difundido, mas pouco efetivo, sobre o atendimento global ao paciente. Isto éparticularmenteimportantequan-

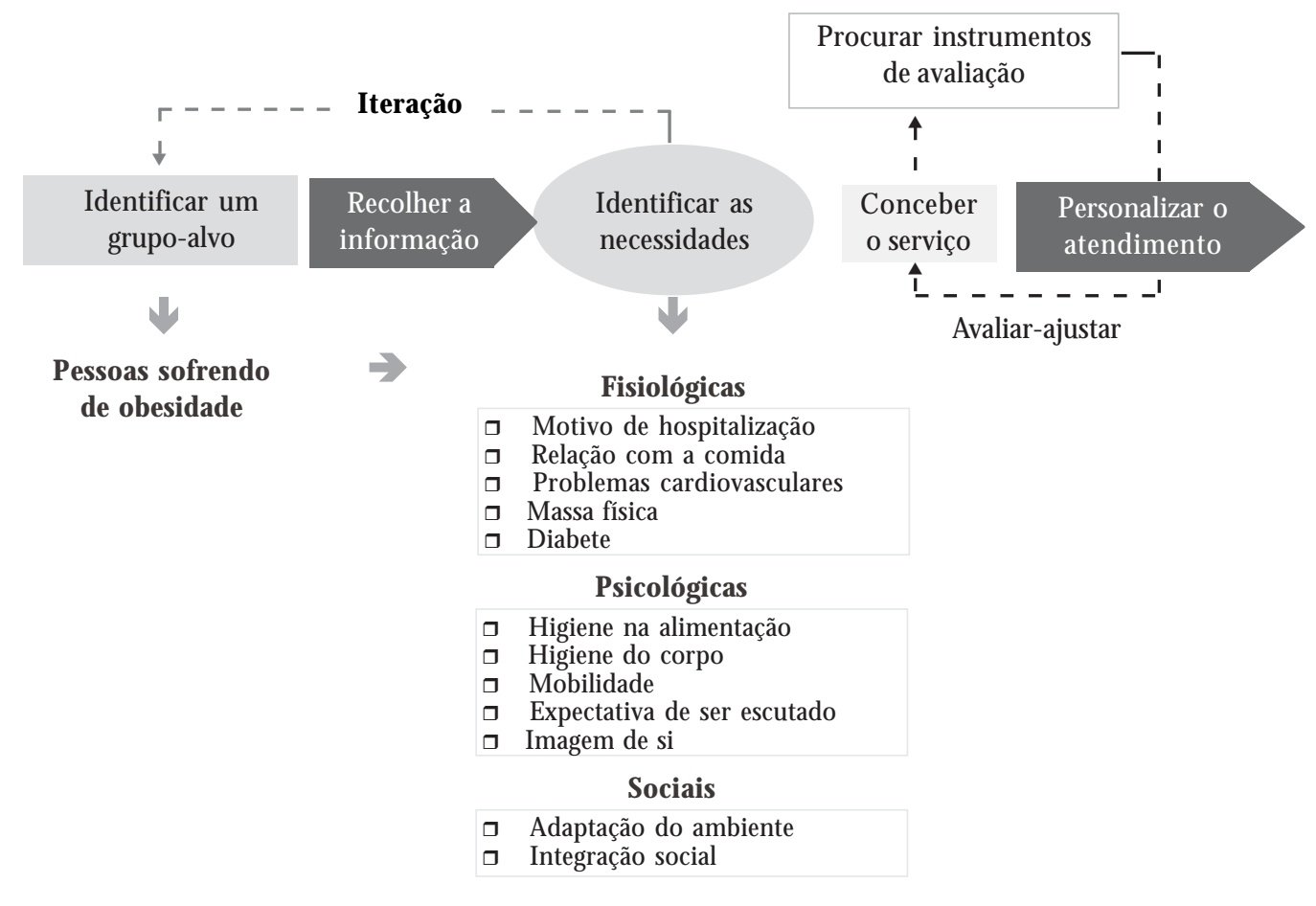

Figura 2. 0 novo modo de raciocínio. 
do se trata de doenças crônicas e/ou degenerativas e/ou do tratamento dos problemas de tabagismo, álcool e drogas. N estes casos, um atendimento parcial não funciona porque precisa atuar num prazo importante sobre os comportamentos e não simplesmente sobre a doença. 0 sucesso depende da capacidade de mobilizar numerosos atores de saúde, de coordenar suas ações, de levar em conta o contexto social efamiliar, de articular-se com os membros das associações de paciente quando existem, entre outras questões.

A criação de val or ligada à concepção eà ope racionalização de serviços complexos é obviamente maior do quea soma das criações devalor ligadas a cada um dos componentes. 0 custo adicional não é proporcionalmente muito elevado na medida em que ele se compõe em parte de um investimento na concepção eem partedecomunicação e de coordenação. Porém, este custo não é previsto pelo seguro social, que deve ser coberto por outras fontes de recursos.

No sistemafrancês caracterizado por uma grandecomplexidade, ligada àconvivência entreprofissionais de saúde de estatuto liberal e operadores institucionais privados e públicos, dotados de importantes graus de liberdade, a necessidade de coordenação dá origem às redes de cuidados coordenados. Evocadas em vários campos do conhecimento, em sociologia4, no campo das inovações sociotécnicas ${ }^{5}$ ou em economia ${ }^{6}$, estas redes são consideradas nos anos noventa como o meio suscetível de revolucionar o sistema de saúde através da implementação experimental de atendimentos complexos. $\mathrm{H}$ oje, elas vivem uma crise na medida em que encontram uma série de problemas. Após vinteanos defuncionamento experimental, a eficácia e a eficiência das redes de cuidados coordenados, financiadas por um fundo específico de inovação do seguro social, são questionadas.

$\mathrm{Na}$ sociologia das organizações, Powell ${ }^{7}$ define as redes como uma forma de organização e de coordenação em que as transações não são feitas de formas atomizadas, nem de autorizações administrativas, mascorrespondem maisaosindivíduos ou instituições empenhadosem atividades recíprocas, preferenciais emutuamente concedidas.

Uma rede de cuidados se compõe do conjunto de atores que participam do atendimento ede uma célula leve, encarregada de animar o processo de concepção do serviço e de facilitar a comunicação entre os profissionais implicados. A abordagem é inovadora na medida em que o ponto de partida do raciocínio é a exploração da demanda, das necessidades e das expectativas dos pacientes, e não a oferta de serviços (Figura 3).
0 papel da rede é de facilitar o trabalho dos profissionais evitando que tenham que cumprir tarefas para as quais não estão preparados, 0 que acontece quando há fal has no entendimento das necessidades do paciente e/ou na articulação e na comunicação entre os profissionais.

As redes podem nascer da iniciativa de profissionais, associações de pacientes ou instituições que, conscientes da inadequação do atendimento a uma população doente específica, querem resolver o problema com todos os atores que deveriam estar implicados no atendimento. Iniciativas informais no começo, podendo existir sem ter uma pessoalidade moral, as redes adotam geralmente uma forma de associação (Lei 1.901), a forma jurídica mais simples na França. Em princípio, o funcionamento das redes não é muito custoso. Porém, atuando num campo amplo e mal definido, podem ser escolhidas formas de desenvolvimento requerendo recursos mais ou menos importantes. Assim, são rapidamente conduzidas a pedir um reconhecimento oficial, pois devem ser credenciadas para se beneficiarem de financiamentos públicos. 0 decreto de 12 de novembro de 1999 criou o Fundo de Ajuda à Qualidade dos Cuidados das Cidades (FAQSV), substituído em 2007 pelo Fundo de Intervenção para a Qualidade e a Coordenação dos Cuidados (FIQCS). Este credenciamento nunca é definitivo, deve ser renovado a cada ano ou a cada três anos no melhor dos casos e os recursos alocados não são estáveis. Esta precariedade está em grande parte ligada a um volume de financiamentos limitado, adequado para incentivar as iniciativas epermitir o funcionamento inicial, não para financiar o funcionamento corrente e o crescimento.

Em termos estratégicos, as redes de cuidados coordenados podem preencher um papel importante como parceiras dos hospitais. Elas podem ajudá-losa inovar na concepção de serviçosintegrados como na busca de uma maior eficácia através de uma boa gestão do fluxo de pacientes (Figura 4). 0 bom uso das alternativas à hospitalização limita a duração da internação, particularmente no campo das doenças de média e de longa duração, graças à articulação de períodos de permanência no hospital, para tratar as fases agudas da doença, e de retorno ao domicílio, durante os períodos de estabilização da doença. Considerando que 0 aspecto mais delicado do processo é a gestão das interfaces entre as diferentes fases do atendimento, as redes, em estreita cooperação com os hospitais, podem assumir as tarefas de coordenação externa que eles não po- 


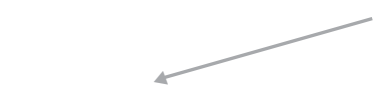

aos profissionais

de saúde

Entendimento e articulação das competências e das contribuições ao longo do percurso global de atendimento

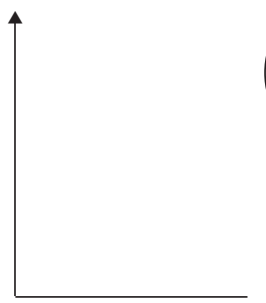

Necessidades expectativas dos pacientes-alvo

Identificação dos profissionais envolvidos
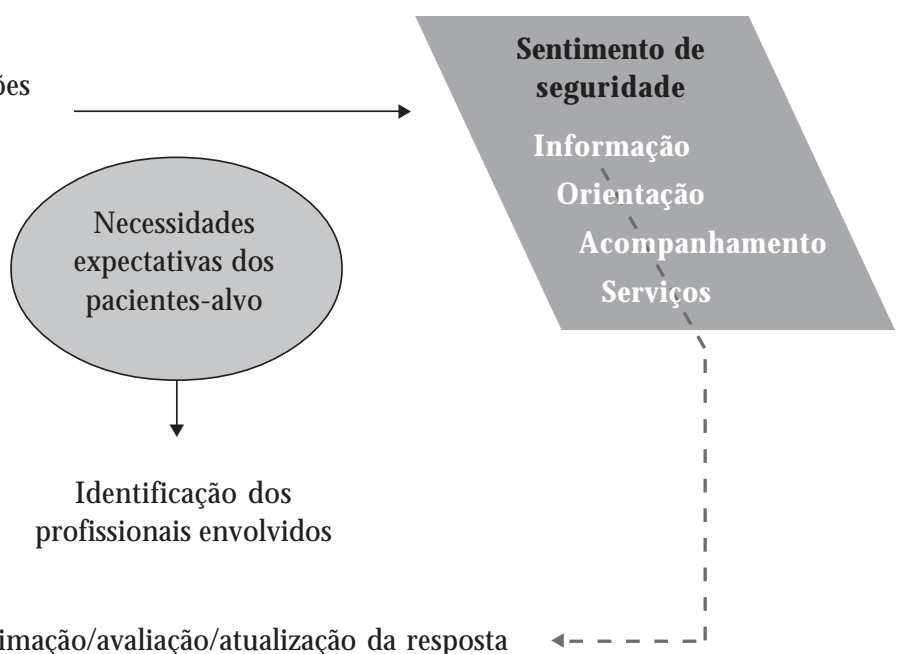

\section{Contribuição}

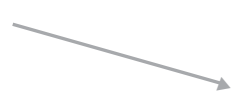

aos pacientes e a

seus familiares

Figura 3. As contribuições de uma rede de cuidados coordenados.

A rede administra os fluxos de serviços convergentes destinados à satisfação das necessidades dos pacientes

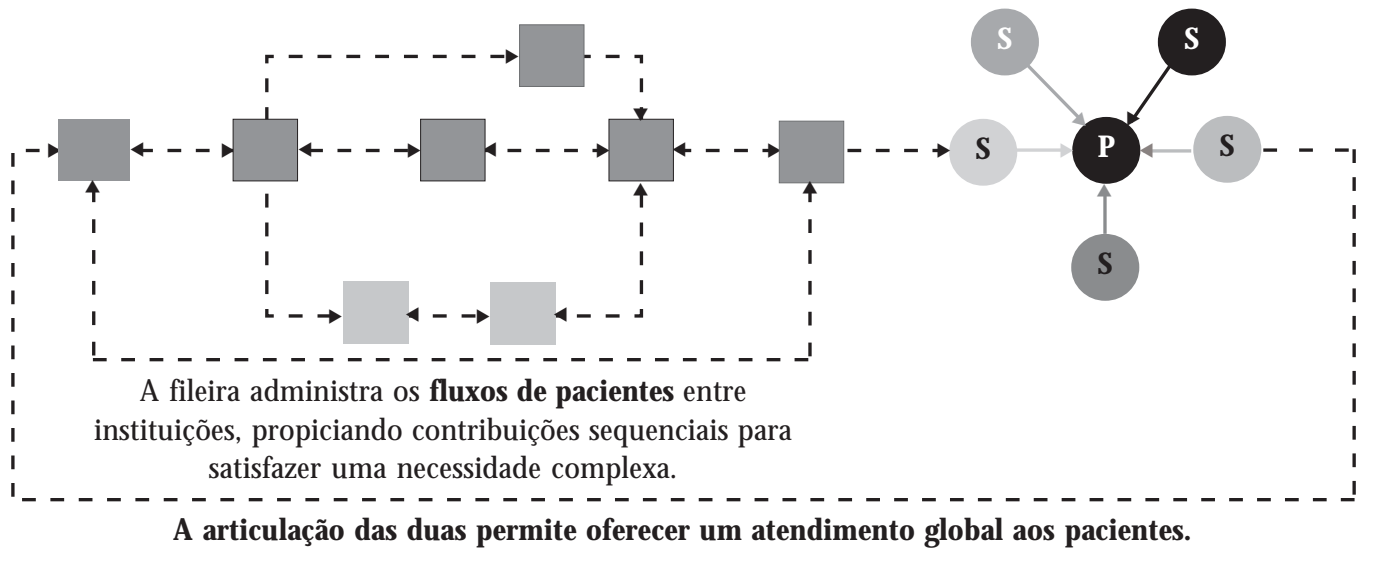

Figura 4. Otimização do atendimento pela gestão de fluxos.

dem realizar com a mesma eficiência. Elas podem, enfim, acompanhar o paciente ao longo do percurso para dar ao atendimento a continuidade e a coerência necessárias. 


\section{As consequências no nível operacional}

H oje, o hospital não pode funcionar sem administrar a interdependência crescente entre os diferentes serviços clínicos, médico-técnicos e administrativos. Por isso, deve mudar de modo de gestão, explicitando os processos internos de "produção" e desenvolvendo as capacidades internas de cooperação. Para administrar os fluxos de pacientes e de prestações, os profissionais de saúde devem ter uma visão precisa e completa do percurso do paciente, fora e dentro do hospital, com o objetivo de evitar hospitalizações inúteis ou inadequadas, controlar os gastos e meIhorar a qualidade de serviço. Numa atividade de mão de obra como os cuidados em saúde, 0 tempo constitui um recurso escasso, tanto para o pessoal como para o paciente, e deve ser economizado, evitando desperdícios. A evolução re centedos modos de atendimento, como o desenvolvimento das hospitalizações de muito curta duração, facilitado pela evolução das técnicas cirúrgicas menos invasivas, aponta neste sentido.

A formalização do percurso do pacientefacilita a organização das contribuições e a otimização da duração da estadia. A antecipação gera o prazo necessário para preparar a saída dos pacientes nas melhores condições. A visão do percurso compartilhada por todos os atores envolvidos permite integrar os constrangimentos ligados aos recursos escassos na concepção do atendimento. A gestão dos processos facilita o trabal ho em equipe e a continuidade do atendimento, ultrapassando as fronteiras organizacionais e culturais. Ela compensa as fraquezas do funcionamento profissional automático e tácito, fruto da estandardização das qualificações, frente à nova complexidade do atendimento. Ela constitui a maior fonte de ganhos potenciais de produtividade graças a uma análise crítica que permite a reformulação dos procedimentos de rotina (Figura 5).

Para difundir esta abordagem, faz-se necessário ultrapassar as resistências relacionadasà cultura médica tradicional, pouco voltada para a formalização das práticas, considerada como um gasto detempo que deveria ser dedicado aos pacientes, somado ao individualismo reforçado pela responsabilidademédicae, por fim, o desconhecimento das técnicas deorganização edecomunicação. É necessário ultrapassar estes limites para desenvolver a cooperação interna entre os profissionais de saúde e entre el es e o pessoal administra-

\section{Administrar os fluxos ligados ao percurso do paciente}

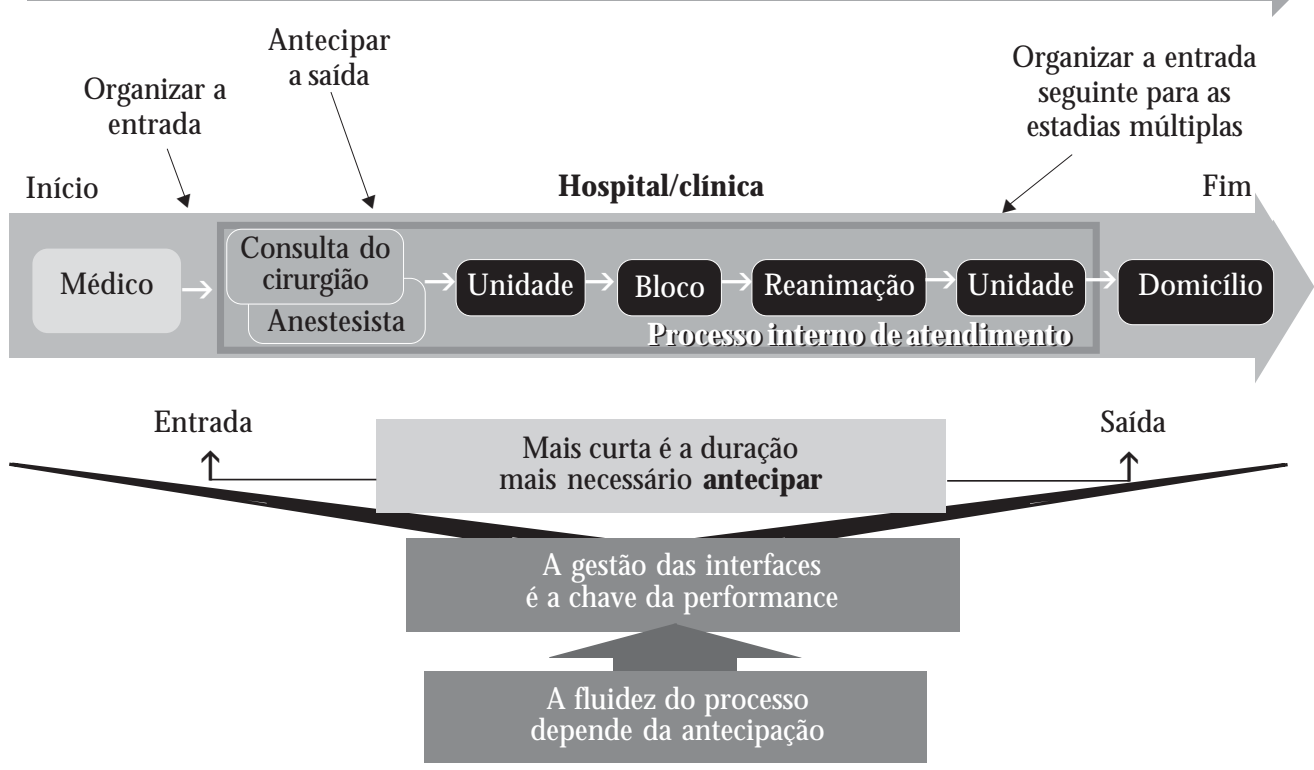

Figura 5. 0 percurso do paciente instrumento de gestão do tempo. 
tivo ededireção. D eve-se considerar que, nos hospitais franceses, os diretores não são médicos. Eles são formados pela Escola dos Altos Estudos em Saúde Pública ou pelas Escolas de Administração, exceto nos Centros Regionais de Luta Contra o Câncer. No hospital moderno, a competência individual não assegura aqual idade do atendimento. Ela depende da capacidade de atuação coletiva necessária para compensar e valorizar a hiperespecialização. Para desenvolver a cooperação interna, épreciso desenvolver os sentimentos de confiança, solidariedade e aceitação mútua, construindo uma linguagem e referências comuns, compartilhando objetivos. Para entrar em cooperação, as pessoas envolvidas necessitam conhecer seus constrangimentos respectivos e usar dos graus de liberdade específicos de cada um para considerar o compromisso satisfatório. Centrar a reflexão na qualidade do atendimento, objetivando as necessidades do paciente, éa principal alavanca para chegar ao consenso e evitar as lutas de poder.

Quando o percurso dos pacientes ultrapassa os limites institucionais, a cooperação interna precisa ser complementada pela cooperação externa. Oferecer serviços mais integrados através uma parceria organizada constitui um progresso evidente para os pacientes e pode ser uma arma potente na competição. $\mathrm{Na}$ França, as ARH se de ram progressivamente conta do interesse de incentivar a cooperação no uso dos equipamentos submetidos à autorização ao invés de usar destas autorizações para dar uma vantagem competitiva a um dos concorrentes em detrimento dos outros. A experiência mostra que, ao contrário, os competidores prejudicados pela decisão acham quase sempre soluções para compensá-la, gerando efeitos perversos que encarecem o custo global deatendimento. As alianças estratégicas oferecem uma alternativa interessante à fusão, principal forma de reestruturação usada nos anos noventa e início dos anos $2000^{\circ}$. Elas permitem a racionalização da oferta de maneira flexível enão definitiva. Para cooperar, é necessário abandonar as relações clássicas de poder para entrar numa dinâmica centrada na realização de um projeto comum, requerendo as contribuições de todos os parceiros paraatingir um objetivo comum suficientemente atraente para ultrapassar as barreiras culturais e os interesses individuais. A mesma abordagem tem que prevalecer qualquer que seja o enfoque interno ou externo da cooperação. N este aspecto cultural, há uma verdadeira sinergia entre as ações de cooperação interna e externa. As duas implicam um processo de aprendizagem progressivo. Para conseguir isto, não se deveraci- ocinar no curto prazo e buscar cedo demais um equilíbrio das contrapartidas entre os parceiros. É necessário limitar o tamanho dos desafios, para facilitar o sucesso das iniciativas, eaumentar pouco a pouco as ambições. É necessário ter uma visão plurianual, assegurando a continuidade na ação, buscando alguns resultados rápidos para favorecer a confiança entre parceiros e alimentar 0 processo de aprendizagem. Para incentivar 0 desenvolvimento das cooperações, instrumentos jurídicos dedicados à área da saúde chamados agrupamentos de cooperação sanitária (GCS) ea comunidade hospitalar de território estão disponíveis na França. M as, se o espírito da cooperação apoiado sobre projetos concretos não presidea assinatura destesacordos, estes transformamse em cascas desesperadamente vazias.

A abordagem pela cooperação coloca o hospital no sistema de saúde como uma organização em rede interna ligada a uma rede externa que estrutura a oferta de serviços num território de saúde?.

\section{Conclusão}

No sistema francês de saúde, os hospitais têm um peso considerável. Eles representam mais de cinquenta por cento do orçamento do seguro social. 0 atendimento primário, por seu lado, é essencialmente constituído por profissionais de saúde (médicos, técnicos de enfermagem) que exercem a profissão individualmente, com um estatuto liberal. As relações entre estas duas principais partes do sistema de saúde são geralmente de tipo individual einformal, de profissional a profissional. Elas são determinadas pela história pessoal de cada um, principalmente durante a formação inicial realizada por uma grande parte nos hospitais. A simultaneidade da formação, do recrutamento e da socialização destes profissionais produz uma integração extremamente potente dos valores e das normas profissionais vigentes. Os comportamentos e as motivações assim constituídos Ihes permitem atuar juntos de maneira quaseinstintiva. A estandardização das qualificações ${ }^{10}$, assim obtida, constitui um fator de estabilidade e de eficácia cuja mudança não é fácil. Ela conduz os profissionais de saúdea identificaremse com o grupo profissional e o grupo de trabaIho estreito no seio do qual atuam no dia a dia. Eles mantêm relações mais distanciadas com a entidade empregadora (hospital, clínica), exceto quando é considerada como ferramenta de trabalho (clínica criada por cirurgiõesacionistas, por 
exemplo) ou quando énecessário defendêla como instituição (o hospital público, por exemplo). Tudo isso forma um contexto político-sócio-organizacional no qual o jogo complexo de poderes e contrapoderes dificulta a busca de coerência e limita as mudanças. Em tal contexto, as reformas dificilmente podem ser conduzidas de cima para baixo de maneira centralizada. Necessitam um envolvimento dos atores numa dinâmica de progressão para o nível local, aproveitando o funcionamento natural em rede para difundir novos modos de atuação. Para conseguir sucesso, é preciso consagrar o tempo necessário para facilitar os intercâmbios, buscar um entendimento comum, achar novas expressões dos valores de base, dos interesses e da solidariedade. N esta jogada, faz-se necessário favorecer a aprendizagem cole tiva para criar novos relacionamentos, intensificar a convergência de experiências e de saberes e desenvolver a confiança mútua. É necessário paciência, mas também tomar rapidamente as me- didas necessárias para definir as novas regras baseadas na evolução efetiva dos comportamentos e dos sistemas concretos de atuação.

Fundado no respeito aos graus de liberdade dos atores, a gestão estratégica parece particularmente bem adaptada à conduta das mudanças neste contexto. Astécnicas de análise e de avaliação usadas envolvem diretamente os interessados, permitindo uma abertura maior ao que acontece fora do mundo estreito do trabalho cotidiano. Elas provocam também uma reflexão fundamental sobreos valores em adequação com os comportamentos reais, permitindo uma evolução da cultura profissional. 0 exame do contexto concorrencial e das oportunidades de cooperação conduz à implementação de novas relações entre os atores individuais e institucionais, modificando efetivamente o funcionamento do sistema de atendimento. Assim, a gestão estraté gica permite embasar a mudança das regras do jogo sobre uma realidade comprovada.

\section{Referências}

1. Crémadez $M$. Les clés de l'évolution du monde hospitalier. Gestion hospitalière 1987; 266:726-731.

2. Crémadez M, Crateau F. Le M anagement Stratégique Hospitalier. Paris: Intereditions; 1992.

3. Couty E. L'enjeu de la contractualisation interne pour les établissements de santé. Gestions hospitalières 2002; 449:285-306.

4. Deresmaux A. Réseaux. In: Le Duff R. Encyclopédie de la Gestion et du M anagement. Paris: Dallot; 1999. p. 1017-1072.

5. Callon M. Réseaux technico-économiques et irréversibilités. In: Boyer R. Figures de l'irréversibilité en économie. Paris: Editions EHESS; 1991.

6. Launois R-J, Majnoni D'Initignano B, Rodwin V, Stéphan J.-C. Les réseaux de soins coordonnés: propositions pour une réforme profonde du système de santé. Revue française des Affaires sociales 1985; 39:37-62.

7. Powell WW. Neither market nor hierarchy: network forms of organization. Research in Organizational Behavior 1990; 12:295-336.
8. Cauvin C, Crémadez M, Dumond JP. In: Gestionnaires et professionnels de santé à l'épreuve des restructurations hospitalières. Paris: Ministére de L'Emploi; 2002.

9. Offner J.-M, Pumain F. Réseaux et territoires - significations croisées. Paris: Editions de l'Aube; 1996.

10. $M$ intzberg $H$. Structures et dynamique des organisations. Paris: Interéditions; 1982.

Artigo apresentado em 06/06/2010

Aprovado em 08/06/2010

Versão final apresentada em 10/06/2010 